
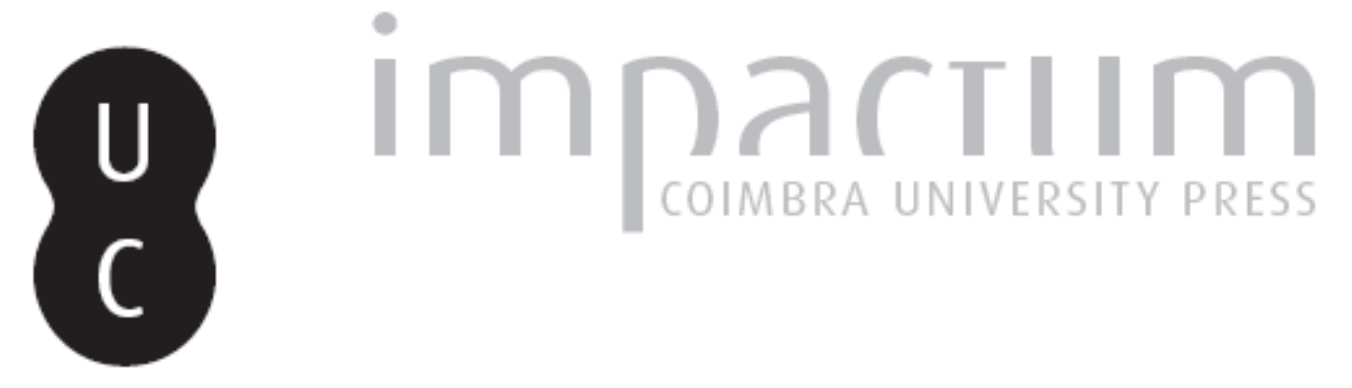
"Morte e vida na Antígona, de Sófocles"
Autor(es): $\quad$ Santos, José Gabriel Trindade
Publicado por: Annablume Clássica; Imprensa da Universidade de Coimbra
URL persistente:
URI:http://hdl.handle.net/10316.2/24335
DOI:
DOI:http://dx.doi.org/10.14195/1984-249X_8_2
Accessed : $\quad$ 26-Apr-2023 13:52:39

A navegação consulta e descarregamento dos títulos inseridos nas Bibliotecas Digitais UC Digitalis, UC Pombalina e UC Impactum, pressupõem a aceitação plena e sem reservas dos Termos e Condições de Uso destas Bibliotecas Digitais, disponíveis em https://digitalis.uc.pt/pt-pt/termos.

Conforme exposto nos referidos Termos e Condições de Uso, o descarregamento de títulos de acesso restrito requer uma licença válida de autorização devendo o utilizador aceder ao(s) documento(s) a partir de um endereço de IP da instituição detentora da supramencionada licença.

Ao utilizador é apenas permitido o descarregamento para uso pessoal, pelo que o emprego do(s) título(s) descarregado(s) para outro fim, designadamente comercial, carece de autorização do respetivo autor ou editor da obra.

Na medida em que todas as obras da UC Digitalis se encontram protegidas pelo Código do Direito de Autor e Direitos Conexos e demais legislação aplicável, toda a cópia, parcial ou total, deste documento, nos casos em que é legalmente admitida, deverá conter ou fazer-se acompanhar por este aviso.

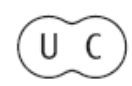


jan.2012

issn $2179-4960$

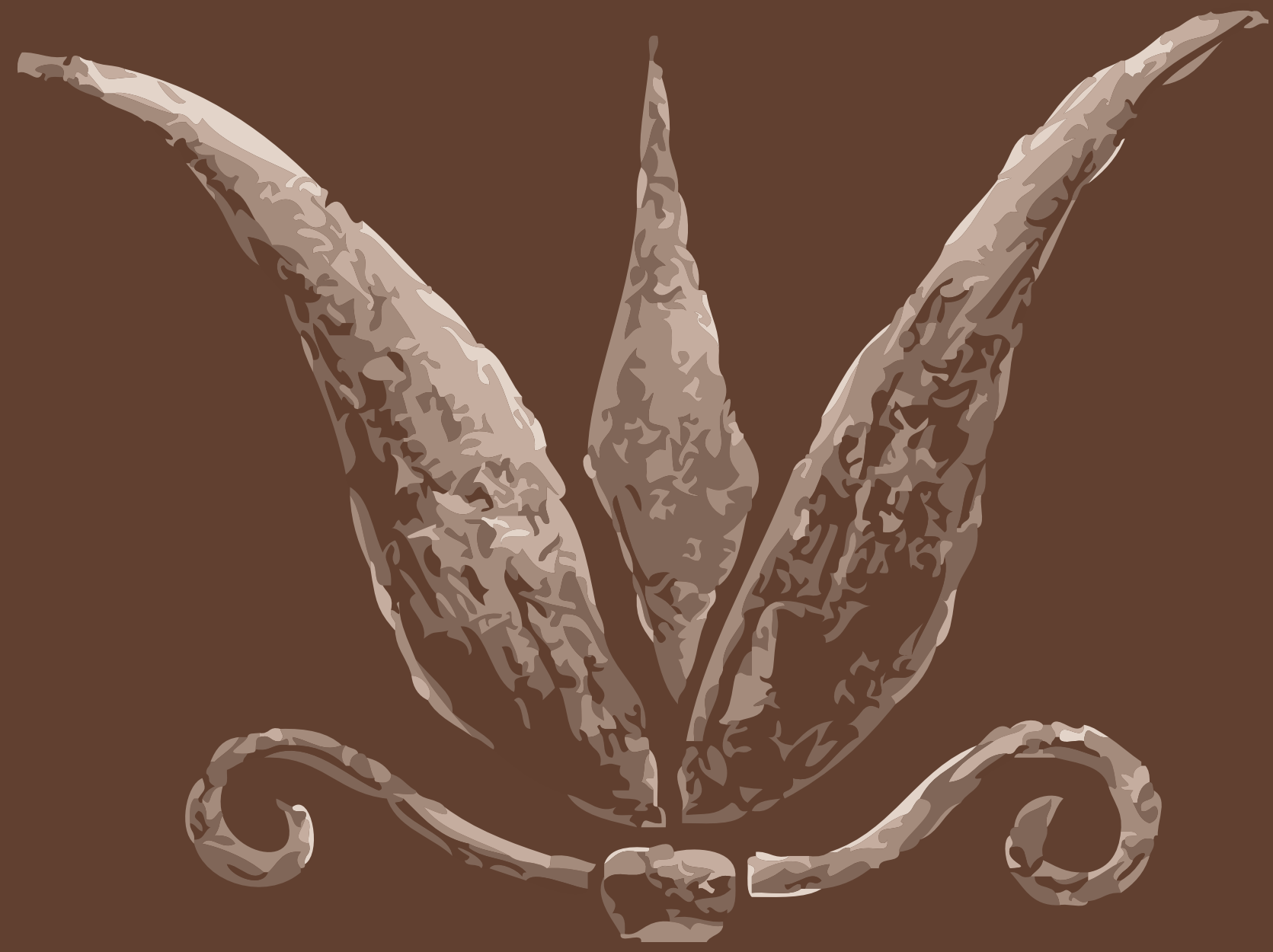

R E V I S T A
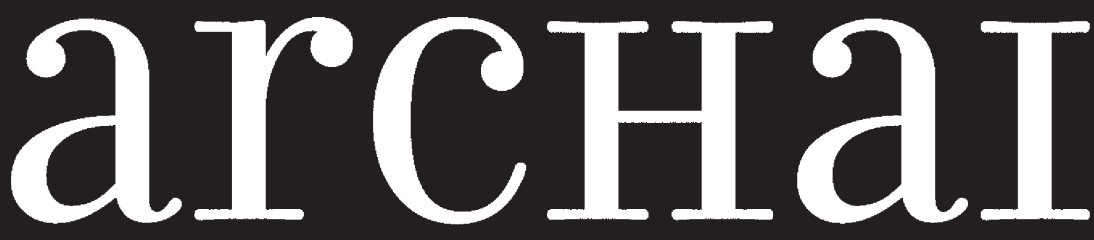

AS ORIGENS DO PENSAMENTO OCIDENTAL

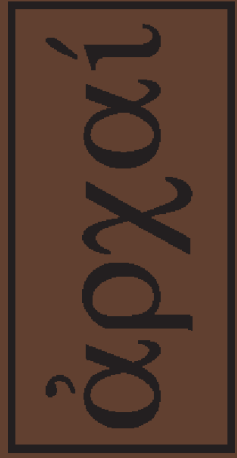

ARCHAI JOURNAL: ON THE ORIGINS OF WESTERN THOUGHT
arcHaI

AS ORIGENS DO PENSAMENTO OCIDENTA.

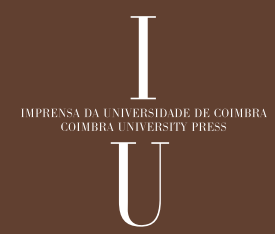

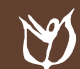




\section{“MORTE E VIDA NA ANTÍGONA, DE SÓFOCLES"}

SANTOS, J. G. T. (2012). “Morte e vida na Antígona de Sófocles". Archai n. 8, jan-jun 2012, pp. 21-25.

RESUMO: 0 conflito descrito na Antígona, de Sófocles, tem habitualmente sido abordado a partir das perspectivas opostas dos protagonistas na peça. Este texto foca a particular relevância dos rituais de sepultamento na construção da trama da tragédia, e, sobre eles, da oposição da "morte" à "vida", nos mundos dos homens e dos deuses. Esta interpretação é complementada por uma releitura da "Ode ao Homem" (332-375).

PALAVRAS CHAVE: Sófocles, Antígona, ritos de sepultamento, Morte/Vida.

ABSTRACT: The conflict represented in Sophocles' Antigone has usually been approached from the opposing perspectives of the protagonists in the play. This text focuses on the particular relevance of the burying rituals in the weaving of the plot of the tragedy and over and above them the opposition of "death" and "life" in the worlds of men and gods. This interpretation is complemented by a rereading of the "Ode on Man" (332-375).

KEY WORDS: Sophocles, Antigone, burying rituals, Death/Life
* Universidade Federal da Paraíba.

Centro de Filosofia da Universidade de Lisboa.

1. Ver no final, as

Referências às obras sobre este tema, usadas na elaboração do texto. As referência à cultura e literatura clássicas vêm nas notas de rodapé.
José Gabriel Trindade Santos*

1. No domínio da antropologia da religião ${ }^{1}$, é possível definir 'rito' como uma prática com a qual uma comunidade visa duas finalidades complementares. Enquanto, por um lado, demarca a transcendência do sacro em relação ao profano, por outro, opera a sua coalescência nele. Esta dualidade se explica pelo fato de a atitude dos humanos perante o "numinoso" (o "potente, incontrolável, e misterioso" poder divino: 0tto 1949) se manifestar por um duplo movimento de atração e repulsão. 0 fenômeno pode ser bem percebido em qualquer rito de passagem, por excelência, no mais definitivo de todos: aquele com que a morte de um membro de uma comunidade é recebida por ela.

0 estudo do comportamento dos grupos primitivos e antigos perante o cadáver do morto documenta bem a dualidade acima referida. 0 rito do sepultamento testemunha o esforço realizado pela comunidade para, aproveitando a persistência do corpo "impuro" do morto (rejeitado pelo sepultamento), assegurar a sua transmutação numa divindade protetora, na forma arquetípica de um antepassado tutelar. Neste quadro, o rito consiste precisamente no conjunto de ações conducentes à sacralização do cadáver.

Entre as diversas formas de ritualização da morte, aquela que atinge a expressão mais complexa 
e profunda é o sacrifício. A finalidade deste é interpor, como protetor ou emissário, uma vítima entre o profano e o sagrado, transformando o seu corpo rejeitado num objeto de troca que permite comprar o acesso da comunidade ao poder divino.

$\mathrm{Na}$ interpretação que vou propor da tragédia Antígona, de Sófocles, tentarei encontrar sinais desta abordagem do tema do rito. Para realizar essa tarefa, terei de acrescentar às informações prestadas pelo texto outras implícitas, às quais um leitor moderno não é sensível, mas que seriam do conhecimento de qualquer espectador ateniense.

2. 0 fascínio exercido pelo conflito descrito na Antígona tem produzido, ao longo dos séculos, inúmeras interpretações tanto no domínio da literatura, como no da cultura, dando ainda origem a muitas imitações, algumas das quais célebres.

Na maior parte delas, é exclusivamente sobre os protagonistas e o seu confronto que os Autores se debruçam. Não é essa a minha intenção com este texto. Viso a dois objetivos. 0 primeiro é mostrar como a concepção de rito acima exposta fornece uma outra perspectiva sobre a natureza do conflito representado na tragédia. Para tal, parto da tese problemática de que todo ele se acha condensado no conjunto de problemas postos à polis pela realização das práticas que adota para levar a cabo a ritualização da morte. 0 segundo objetivo decorre deste e prende-se com a análise do comportamento dos protagonistas, procurando, neste contexto, avaliar a mensagem didática da tragédia.

2.1 No Prólogo, o diálogo em que Antígona pede a Isménia que a ajude a sepultar o seu irmão Polinices mal nos deixa perceber o que mais tarde será declarado por Tirésias: à roda de Tebas centenas de cadáveres jazem insepultos (1080-1083).

$\mathrm{Na}$ véspera, os tebanos terão sepultado os seus mortos e erigido um troféu com as armas capturadas ao inimigo. Presumivelmente durante a cerimónia com que honraram Etéocles, Creonte terá anunciado a decisão de deixar insepultos os cadáveres dos soldados invasores, entre os quais se conta o de Polinices.

Esse propósito - que no início da peça Antígona tinha mostrado conhecer - é reafirmado no discurso que o príncipe dirige à Assembleia, que coroa $01^{\circ}$ episódio. A partir desse momento, a ação vai colocar o espectador diante de situações concretas, fazendo-o por momentos esquecer que todas elas se desenrolam com o espectro da morte pairando sobre a cidade.

É o caso das cenas tragicómicas dos dois diálogos de Creonte com o guarda, que servem para descrever as repetidas tentativas de celebração do rito de sepultamento de Polinices, a segunda das quais conduziu à prisão de Antígona. Após a recitação da "Ode ao Homem", que constitui o $2^{\circ}$ estásimo da tragédia, ei-la que se mostra no palco acorrentada, confessando prontamente ter violado a proibição.

A violência do embate da agressividade raivosa de Creonte com a atitude desafiadora da filha de Édipo levou os comentadores a explicarem o confronto de perspectivas muito diferentes. Todos prestam, porém, a maior atenção às palavras com que a heroína explica a sua infração ao édito de Creonte:

"É que essas não foi Zeus que as promulgou, nem a Justiça que coabita com os deuses infernais estabeleceu tais leis para os homens. E eu entendi que os teus éditos não tinham tal poder, que um mortal pudesse sobrelevar os preceitos não escritos, mas imutáveis dos deuses. Porque esses não são agora, nem de ontem, mas vigoram sempre, e ninguém sabe quando surgiram" ${ }^{\prime 2}$ (450-457).

Hegel remete a explicação para a conflito entre o direito familiar e o do Estado ${ }^{3}$, mas essa leitura foi considerada redutora, não sendo mais aceita hoje. Outros recorrem a argumentos de natureza política ou psicológica ${ }^{4}$. Todos concorrem, contudo, na importância atribuída à referência às “leis não-escritas", embora a interpretem de modos muito diferentes.

Contra a generalidade dessas interpretações, defendo aqui uma leitura ampla - já proposta noutros escritos ${ }^{5}$ - de que as leis a que Antígona alude são simplesmente as da morte e da vida, como aqui vou defender que a sequência da peça mostrará.

Neste sentido, parece-me ser necessário fazer uma distinção, separando o conflito propriamente dito, que condenso no estudo das motivações de
2. A tradução de M. Helena da Rocha Pereira, Antígona, Sófocles, Coimbra 1984, será usada em todas as citações da tragédia.

3. Ästhetik 2. Teil, 1. Kap. 2b. Note-se, porém, que nem Creonte é o Estado, limitando-se a servir-se dele, nem Antígona é a família, mas a sua família, perseguida pela maldição (vide a crítica em A. Lesky, Historia de la Literatura Griega, Madrid 1985, 307-309). Ver bibliografia relevante em $\mathrm{J}$. T. Santos "Antígona: a mulher e o Homem", Humanitas, XVI (1995), 115-138.

4. Por exemplo, C. Segal, "Sophocles' Praise of Man and the Conflicts of the Antigone", in Sophocles: a Collection of Critical Essays, Englewood Cliffs (New Jersey) 1966, 62-85.

5. "ANTÍGONA: a Mulher e 0 Homem"; "A natureza e a lei: reflexos de uma polémica em três extos da Grécia Clássica", Estudos sobre Antígona, Victor Jabouille (org.), Lisboa 2000, 107-111; "Antígona sem explicações", Hypnos 15, 2005, 2, 69-84. 
6. Manifesto na sua tentativa de alijar responsabilidade pelo suplício não só evitando o derramamento de sangue, como ainda provendo a vítima com algum alimento (772-780).

7. 0 problema da motivação "patriótica" daquele que atac

a sua cidade para restabelecer um regime deposto é comum na história das cidades gregas (ver o discurso de Alcibíades aos

Lacedemónios, no qual se justifica por querer reconquistar a sua cidade: Tucídides História VI92, 2-4: vide o reflexo do conflito a dúvida de Aristóteles, Política III3,1276a8-b15).

8. Note-se o novo dilema em que Creonte se acha. Se tivesse posto fim à vida de Antígona antes de a sepultar, não a teria enviado viva para o reino dos mortos. Mas então incorreria num miasma de cujos riscos se mostra bem consciente (773-780).

9. Semelhante às armadilhas estendidas a Laio e Édipo. Se o re não tivesse ordenado a execução do filho, ou este fugido para Corinto e sido adotado pelo rei, a maldição não se cumpriria.

10. Não há afecto entre olímpicos e infernais (1072-1073). Ess revelação deverá pesar sobre a devoção de Antígona à "Justiça que coabita com os deuses infernais" (450-451). Note-se que implicitamente a referência se limita à parte da Justiça, relativa aos infernais (vide W. Burkert, Religião grega na Época Clássica e Arcaica, Lisboa, 1993, 393).

11. A natureza da "lei divina" a que a heroína se refere (450-7) não é clara, e tem dado origem a enorme controvérsia, constituindo um dos pontos em torno dos quais a generalidade dos comentadore condensa a sua interpretação da tragédia. 0 único aspecto que não dá margem a dúvidas é o da sua oposição ao decreto de Creonte. Pode, porém, englobar quesitos muito diversos. Num dos extremos, poderá visar o ultraje da piedade fraternal, acima aludida, no outro - que me parece bem mais importante - , o desrespeito pela sacralidade da morte.

12. Esta falta será ainda potenciada por uma série de pormenores genuinamente teatrais. Após ter dado ordem para libertar a jovem $(1100,1110)$
Creonte para as decisões que toma, dos extremos a que se deixa levar. Distingo ainda a sua não anuência ao sepultamento de Polinices da violência que exerce sobre Antígona, expressa no cinismo cruel que envolve a execução da sentença a que a condena ${ }^{6}$. Mas quero aqui acrescentar uma nota.

2.2 Os erros de Creonte são muitos. Aquele que é dado a conhecer ao espectador por Tirésias no $5^{\circ}$ episódio da tragédia terá consistido em violar a lei divina que obriga a respeitar os mortos (1015-1033, 1064-1084). Como Antígona mostrou ter percebido, o erro é ainda mais grave no caso de Polinices, por proibir a comunidade de realizar os ritos que evidenciam o respeito pelo cadáver de um seu morto. Mas o príncipe não se dá conta de que com essa justificável decisão está a atrever-se a legislar sobre o reino dos mortos, no qual só os deuses infernais têm poder.

Todavia, a Antígona é uma obra destina à cena, pois, o drama não consente que o espectador dê conta do dilema em que Creonte se acha. Sepultar Polinices é obrigar a cidade a acolher como amigo aquele que, como inimigo, a invade, reconhecendo-o como figura tutelar. Ora, aos olhos de quem honra Etéocles, essa dignidade não poderia ser concedida ao seu irmão que pôs em risco a sobrevivência da cidade, fazendo aliança com os tradicionais inimigos de Tebas'

Mesmo assim, o erro original de Creonte pouca importância teria se não fosse agravado pela sua intransigência, expressa na injustificável série de gravosas decisões que vai tomar. Primeiro, o sepultamento, sacrílego, do ponto de vista ritual, de Antígona - viva, provida de alimento e sem efusão de sangue ${ }^{8}$, porém, privada de ritos funerários (1207) - compõe a confusão operada entre os reinos da morte e da vida. Depois, o não reconhecimento das razões de Hémon e dos seus direitos de noivo leva-o a atentar contra a divindade do amor, oportunamente celebrado no $3^{\circ}$ estásimo da tragédia.

Tudo isto o espectador gradualmente aprende ao longo do diálogo entre Creonte e Tirésias (9891091). No que diz respeito a Polinices, que só no final da intervenção do adivinho (1015-1023, 1080 1084) sabemos jazer ao lado dos cadáveres dos invasores, Creonte é culpado por deixar insepultos os seus corpos (1016-1020: é essa afinal a causa da peste que desencadeia o seu tardio arrependimento). No que concerne Antígona, é também culpado por a enclausurar viva numa gruta. Esse ato parece incidir apenas sobre a jovem, no entanto, conduzirá a um triplo suicídio.

0 primeiro é o da heroína, que se enforca com um fio de tecido. 0 segundo é o de Hémon, filho de Creonte, chegado tarde demais para libertar a sua noiva; suicídio misteriosamente anunciado no diálogo travado por pai e filho:

"Ela morre, mas ao morrer causará a perda de alguém" (751).

0 príncipe de Tebas acabará assim punido pelas proporções cada vez mais tremendas das consequências a que a sua falta deu origem. Nunca chega a entender a armadilha que os deuses the estendem ${ }^{9}$. Enquanto o respeito pelos deuses olímpicos o impede de celebrar o rito de sepultamento de Polinices, 0 culto dos infernais devia obrigá-lo a respeitar os mortos $^{10}$. Por não se aperceber da situação em que se acha, ignora os protestos de Antígona, atentando contra a lei não-escrita que separa vivos de mortos e os direitos de uns deuses dos outros ${ }^{11}$.

Como já disse, peca ainda contra o Amor $\left(3^{\circ}\right.$ estásimo: 781-800), ao não dar ouvidos ao filho, a quem por direito caberia trazer à razão e à ordem a prometida esposa. Mas, acima de tudo, atenta contra os deuses infernais, por não respeitar os mortos, deixando-os insepultos entre os vivos e enterrando uma viva no reino dos mortos ${ }^{12}$.

No entanto, o culminar da desventura de Creonte ainda está para vir. A chegada à sua mulher Eurídice da notícia da morte de Hémon evoca na mãe devastada a memória do sacrifício do filho mais novo - Meneceu ou Megareu - ordenado por Creonte para salvar a cidade dos invasores ${ }^{13}$ (a revelação é feita indiretamente pelo segundo mensageiro, que relata o suicídio e a maldição de Eurídice: 13011305, 1312-1313).

Por todas as consequências dos seus atos, no êxodo da tragédia, Creonte acha-se totalmente destruído, tendo aprendido a extensão das consequências dos erros cometidos: 
".......................... tudo"

Que tenho nas mãos está abalado; sobre mim

Impende um futuro

Que não se suporta" (1344-1348).

É nesse momento que, como o Coro comenta na sua intervenção final, recebe o ensinamento que os deuses the destinaram:

"Para ser feliz, bom-senso é mais que tudo.

Com os deuses não seja ímpio ninguém.

Dos insolentes palavras infladas

Pagam a pena dos grandes castigos;

A ser sensatos os anos lhe ensinaram." (1349-1353)

Estas palavras, no final da peça, bastam para colocar Creonte no foco da tragédia - como digno representante da Humanidade -, elevando Antígona à dignidade de referência lendária ${ }^{14}$. 0 Príncipe é 0 destinatário de todas as lições que os deuses destinam aos Humanos, condensadas na advertência relativa ao saber, à aprendizagem e à ambivalência da técnica. Focadas na Ode ao Homem, constituem o tema dominante na tragédia, desde a primeira intervenção de Creonte (173-210) até à última palavra pronunciada na peça ${ }^{15}$ (1353).

3. Por tudo isto é necessário responder a uma pergunta capital: que devia Creonte ter aprendido? Decerto, a lição dada aos espectadores da tragédia logo que a segunda antístrofe da "Ode ao Homem" foi recitada. Vale, contudo, a pena citá-la integralmente, pois a chave da tragédia acha-se na ambivalência que a percorre:

“Muitos prodígios ${ }^{16}$ (ta deina) há: porém nenhum maior do que o homem.

Esse, co'o sopro invernoso do Noto,

Passando entre as vagas

Fundas como abismos,

O cinzento mar ultrapassou. E a terra

Imortal, dos deuses a mais sublime,

Trabalha-a sem fim,

Volvendo o arado, ano após ano,

Com a raça dos cavalos laborando.

E das aves as tribos descuidadas, $\left(332-375^{17}\right)$

A raça das feras,

Em côncavas redes,

A fauna marinha, apanha-as e prende-as

0 engenho (periphradês) do homem.

Dos animais do monte, que no mato

Habitam, com arte (mêchanais) se apodera;

Domina o cavalo

De longas crinas, o jugo the põe,

Vence o touro indomável das alturas.

A fala e o alado pensamento,

As normas que regulam as cidades

Sozinho aprendeu:

Da geada do céu, da chuva inclemente

E sem refúgio, os dardos evita,

De tudo capaz (pantaporos),

[em nada incapaz, arrosta o futuro] (aporos ep'ouden erchetai).

Ao Hades somente

Fugir não implora.

De doenças invencíveis os meios

De escapar já com outros meditou.

Da sua arte o engenho subtil (sophon ti mêchanoen | technas)

P'ra além do que se espera, ora o leva

Se da terra preza as leis e os deuses

Na justiça faz fé, grande é [n] a cidade (hypsipolis);

Mas logo a perde (apolis)

Quem por audácia incorre no erro.

Longe do meu lar

0 que assim for!

E longe esteja dos meus pensamentos

0 homem que tal crime perpetrar!"

Em Sófocles, "as normas que regulam as cidades" refletem, como obras que são "da fala e do alado pensamento ${ }^{18}$ ", o esforço pelo qual "sozinho" o homem se guindou à posição de senhor da criação. Mas, "sozinho" porquê?

Sozinho por gradualmente ter aprendido a dominar os outros animais, elevando a sua ousadia aos deuses, de cujo jugo tenta se liberar. Consegue-o através da polis, na 0de, apontada como a akmê do
Ao bem, ora ao mal;
Creonte se decide a celebrar os funerais de Polinices (1197-1205), enquanto deixa Antígona a morrer, enterrada viva. É claro que quando chega à caverna a encontra já morta nos braços do filho, que terá partido para a libertar talvez após o arrependimento do pai, e se suicida diante dele.

13. Fato certamente conhecido das audiências da peça em Atenas; ao contrário do que acontecerá com as de outros tempos e lugares.

A muda acusação de Eurídice remete para os acontecimentos narrados por Ésquilo em Sete contra Tebas. A crer no que nos é relatado pelas Fenícias, de Eurípides, 912 ss., 1090 ss., poderá ter sido forjada por Sófocles. 0 próprio adivinho se atribui responsabilidade pela indicação que conduziu ao sacrifício de Meneceu quando desafia Creonte com a resposta seca: "graças a mim salvaste a cidade" (Antígona, 1058).

14. Como o Coro confirma nos anapestos que se seguem à segunda estrofe do terceiro episódio (781-806) e no subsequente diálogo com o Coro (807-883).

15. Ao longo da peça, personagens e Coro não cessam de se referir ao pensamento (175, $352,376,479,510,635,664$, 683, 707, 727, 754, id., 1051, $1229,1347,1352)$, linguagem $(352,604)$, razão $(648,1261)$, alma (175, 708), sensatez/ insensatez (1269) e finalmente, aprender (710, 723, 1089-1090, 1353), além das muitas referências passageiras a saber, sábio e sabedoria.

16. Entre as muitas traduções que a Ode recebeu, o ambivalente termo "prodígios" parece-me ser aquele que mais fielmente preserva o traço com que Sófocles caracteriza o Homem: a sua capacidade de obrar "bem ou mal" (365-367). Tal como a continuação da Ode e a sequência da acção ilustram, é a inevitabilidade da manifestação do erro nos seus empreendimentos que melhor caracteriza o Homem.

17. Tradução de M. Helena da Rocha Pereira, Antígona, Sófocles, Coimbra 1984.

18. "Alado" porque, saindo pela boca, atinge aqueles a quem se dirige. 
progresso da Humanidade. Por isso, na Antígona, a cidade e as leis que a regem participam tanto na construção da trama, quanto os protagonistas na acção. No plano ideológico, todas as personagens nomeadas no drama, ilustram os extremos a que conduz o conflito das leis não-escritas com o decreto promulgado pelo príncipe (175-192).

No entanto, o conflito pessoal de Creonte é apenas mais um exemplo do quadro em que, no plano da acção, o dramaturgo não deixa de mostrar como as leis humanas inexoravelmente vão arrastando a estirpe dos Labdácidas para a sua perda. 0 poder os eleva, o poder os expulsa (veja-se a contraposição hypsipolis/apolis - "grande na cidade"/"sem pátria" -, com que termina a 0de).

Esta alternância documenta perfeitamente a ambivalência das artes que geraram a cidade, sempre levando ora ao bem, ora ao mal. Este é um tema introduzido por Sófocles, ao qual Platão prestará toda a atenção ${ }^{19}$. Toda a produção artística é avaliável de perspectivas, por vezes conflitantes, pois, abundam os exemplos de peças, tecnicamente "bem feitas", terem gerado consequências eticamente "más" ${ }^{20}$.

É, pois, para a necessidade de zelar pela manutenção do equilíbrio entre os planos interdependentes da Técnica e da Ética que a advertência aponta; acima de tudo, para a imperiosa necessidade de sustentar o progresso social num correspondente progresso moral.

0 modo como Creonte decide proibir o sepultamento de Polinices evidencia a sua competência política. No entanto, a obstinação que revela na execução dessa decisão torna patente a sua incapacidade para exercer com justiça o poder que detém sobre os seus súbditos. 0 próprio filho disso 0 adverte:

"Mandarias bem numa ilha deserta" (739).

Consequentemente, em conformidade com o diagnóstico realizado pelo dramaturgo, as expectativas humanas não podem deixar de ser sombrias. Nessa medida, o preço a pagar pelo problemático progressismo de Sófocles é um prudencial pessimismo. Com Antígona imolada na ara do desespero, Hé- mon e Eurídice sacrificados à obstinação de Creonte, e o senhor da cidade vítima da sua cegueira, triste é a sorte reservada aos humanos.

Daí a necessidade de uma nova Ética que sustente o futuro da cidade, pois, a culminância a que o Homem se elevou, resultante do domínio a que submeteu a natureza, só tornará mais grave a sua queda, se não se aperfeiçoar na virtude.

Os deuses saíram da cena, agindo de longe. Sozinho, ficou o homem na cidade. Mas este, com a sua ascensão, passou a servir dois novos senhores: a natureza, da qual "progressivamente" se vai afastando, e as leis tanto a divina, quanto a humana, com as quais não se mostra capaz de aprender a conviver.

Por isso, após a saída de Tirésias, a morte toma definitivamente conta da cena. Sucedem-se o sepultamento de Polinices, a representação da morte de Antígona, à qual se segue a de Hémon, finalmente a da mãe dos imolados filhos de Creonte.

É então que o príncipe aprende. 0 quê? Pura e simplesmente, a morte dos seus dois entes mais queridos te-lo-á ensinado a perceber quão terríveis podem ser as consequências de confundir vivos com mortos (1064-1091).

Todavia, na vertigem da ironia trágica, só o espectador atento da peça terá reparado que, para que a lição seja efectiva, é apenas necessário que Creonte continue vivo. Naquele momento em que mais que tudo anseia pela morte, essa única consolação que os deuses lhe poderiam conceder, é-lhe emblematicamente negada, ao ser arrastado pelos servos para fora de cena (1307-1311, 1317-1325, 1329-1333).

\section{REFERÊNCIAS BIBLIOGRÁFICAS}

DURKHEIM, É. (1912). Les formes élémentaires de la vie réligieuse, Paris.

FRAZER, J. G. (1965). The Golden Bough 1890. S. Freud, Totem et tabou, Paris.

HUBERT, M. \& MAUSS, M. (1929). Mélanges d'histoire des réligions, Paris.

LÉVI-STRAUSS, C. (1962). La pensée sauvage, Paris.

OTT0, R. (1949). Le Sacré, Paris.

Recebido em novembro de 2011. Aprovado em dezembro de 2012. 